\title{
Teaching Quantitative Reasoning: A Better Context for Algebra
}

Eric Gaze

Bowdoin College, egaze@bowdoin.edu

Follow this and additional works at: https://digitalcommons.usf.edu/numeracy

Part of the Science and Mathematics Education Commons

\section{Recommended Citation}

Gaze, Eric. "Teaching Quantitative Reasoning: A Better Context for Algebra." Numeracy 7, Iss. 1 (2014): Article 1. DOI: http://dx.doi.org/10.5038/1936-4660.7.1.1 


\title{
Teaching Quantitative Reasoning: A Better Context for Algebra
}

\begin{abstract}
This editorial questions the preeminence of algebra in our mathematics curriculum. The GATC (Geometry, Algebra, Trigonometry, Calculus) sequence abandons the fundamental middle school math topics necessary for quantitative literacy, while the standard super-abundance of algebra taught in the abstract fosters math phobia and supports a culturally acceptable stance that math is not relevant to everyday life. Although GATC is seen as a pipeline to STEM (Science, Technology, Engineering, Mathematics), it is a mistake to think that the objective of producing quantitatively literate citizens is at odds with creating more scientists and engineers. The goal must be to create a curriculum that addresses the quantitative reasoning needs of all students, providing meaningful engagement in mathematics that will simultaneously develop quantitative literacy and spark an interest in STEM fields. In my view, such a curriculum could be based on a foundation of proportional reasoning leading to higher-order quantitative reasoning via modeling (including algebraic reasoning and problem solving) and statistical literacy (through the exploration and study of data).
\end{abstract}

\section{Keywords}

quantitative reasoning, STEM education, proportional reasoning, modeling, statistical literacy

Creative Commons License (c) (1) (3)

This work is licensed under a Creative Commons Attribution-Noncommercial 4.0 License

\section{Cover Page Footnote}

Eric Gaze is President of the National Numeracy Network. A mathematician, he is the Director of the Quantitative Reasoning Program at Bowdoin College, and Lecturer in the mathematics department. Eric has been involved with developing QR curricula for over 15 years and leads workshops around the country on teaching and assessing QR. 


\section{Introduction}

There has been a steady growth of QR-type courses since 1995 with Math for the Liberal Arts and Finite Math enrollments rising 63\% from 195,000 students in 1995 to 318,000 students in 2010 (Table 1). ${ }^{1}$ Meanwhile, Calculus I enrollments rose only $20 \%$ over the same period, from 250,000 to 300,000 It is worth underscoring that the two general education math courses exceeded mainstream Calculus I enrollments 318,000 to 300,000 in fall 2010.

\begin{tabular}{|c|c|c|c|c|}
\hline \multicolumn{5}{|c|}{$\begin{array}{l}\text { Conference Board of Mathematical Sciences } 2010 \text { Survey* } \\
\text { (Enrollments in thousands) }\end{array}$} \\
\hline & 1995 & 2000 & 2005 & 2010 \\
\hline \multicolumn{5}{|l|}{ Two-year colleges } \\
\hline Finite Math & 24 & 19 & 22 & 18 \\
\hline Liberal Arts Math & 38 & 43 & 59 & 91 \\
\hline Calculus I & 58 & 53 & 51 & 65 \\
\hline \multicolumn{5}{|c|}{ Four-year colleges and universities } \\
\hline Finite Math & 59 & 82 & 94 & 62 \\
\hline Liberal Arts Math & 74 & 86 & 123 & 147 \\
\hline Calculus I & 192 & 192 & 201 & 235 \\
\hline
\end{tabular}

Even so, Math for Life: Crucial Ideas You Didn't Learn in School by Jeffrey Bennett (Bennett 2012; Gaze 2012) raises the still-relevant question of why the current mathematics curriculum is so devoid of the material needed to navigate our personal worlds of finance, business, and citizenship. We in the National Numeracy Network and the QR movement are undoubtedly familiar with the rationale for the "GATC" sequence (Geometry, Algebra, Trigonometry, Calculus). It is billed as a pipeline to the STEM fields (Science, Technology, Engineering, and Mathematics) and, hence, the critical professions that drive job growth and scientific/technological innovation. Conventional wisdom dictates that calculus, in particular, holds pre-eminent status as the gateway to STEM. Fifty years ago, if you asked STEM faculty in universities and colleges for the mathematical pre-requisites for success in calculus, they undoubtedly would reply algebra, with a bit more algebra, some trig, and then more algebra. Not only does the GATC sequence completely abandon the fundamental middle school math topics necessary for quantitative literacy but this super-abundance of algebra taught in the abstract fosters math phobia and supports the culturally acceptable stance that math is not relevant to everyday life.

\footnotetext{
${ }^{1}$ Data are from the CBMS 2010 Survey of Undergraduate Mathematical Sciences Programs (Conference Board of the Mathematical Sciences). For the full report, see Blair, Kirkman, and Maxwell, 2013.
} 
The unquestioned super-importance of algebra has been close to gospel in the mathematics education community. U.S. Secretary of Education Arne Duncan's speech April 15, 2011, to the National Council of Teachers of Mathematics (NCTM) contains the line: "Algebra is the key to success in college." 2 Educators are, however, beginning to question this bold claim. Consider NCTM President Michael Shaughnessy's message in February 2011 titled: "Endless Algebra - The Deadly Pathway from High School Mathematics to the College Mathematics"3 This is a good example of two well-meaning advocates arriving at radically opposed positions while looking at the same data: Of the 4,012,770-member cohort of 2001 9th graders, only 1,303,050 were college-ready in fall 2005 and only 166,530 graduated with a STEM degree in the next six years (on or before May 2011). The paltry 166,530 STEM degrees (4\% of the entering $9^{\text {th }}$ grade cohort) led Secretary Duncan to conclude we are experiencing a STEM crisis and need to increase the numbers of STEM graduates by "increasing the rigor of what is taught in the classroom" (i.e., algebra). Mike Shaugnessy, on the other hand, looks at the other 3,846,240 students (96\%) for whom the "tunnel of repetitive algebra” paid no dividends and sees a $Q R$ crisis; he asks for a better mathematical experience for these students.

Just how crowded is this tunnel of repetitive algebra? The developmental math program at two-year colleges is centered on algebra with $61 \%$ of all math enrollments at two-year schools in Fall 2010 in some flavor of algebra (Table 2). This statistic is even higher given that $30 \%$ of two-year schools have their precollege level math programs offered outside of the math department in developmental (remedial) programs.

Table 2

Enrollments in Math Courses at Two-Year Colleges* (Enrollments in thousands)

\begin{tabular}{lrrrrr}
\hline & 1990 & 1995 & 2000 & 2005 & 2010 \\
\hline Pre-College Level & & & & & \\
Pre-Algebra & 45 & 91 & 87 & 137 & 226 \\
Elementary Algebra (HS level) & 262 & 304 & 292 & 380 & 428 \\
Intermediate Algebra (HS level) & 261 & 263 & 255 & 336 & 344 \\
\hline Pre-Calculus Level & & & & & \\
College Algebra & 153 & 186 & 173 & 206 & 230 \\
College Algebra + Trigonometry & 18 & 17 & 16 & 14 & 11 \\
Total & 1272 & 1425 & 1347 & 1696 & 2024 \\
\hline
\end{tabular}

* Blair et al. 2013

\footnotetext{
2 http://www.ed.gov/news/speeches/math-teachers-nation-builders-21st-century (accessed 11 June 2012)

${ }^{3}$ http://www.nctm.org/about/content.aspx?id=28195 (accessed 11 June 2012)
} 
For students enrolled in these courses, algebra is not so much the key to success in college as the barrier to entry. To continue to teach these students the standard form of algebra over and over hoping for a better result is pointless. What is needed is a better way to teach algebra. A rigorous QR course can provide just the setting by grounding algebra in real-world context. The QR community appreciates the severity of the STEM crisis and does not see addressing the QR crisis (creating quantitatively literate citizens) as being at odds with creating more scientists and engineers. In some sense, they are two sides of the same coin. The QR community seeks to create a curriculum that addresses the quantitative reasoning needs of all students, providing meaningful engagement in mathematics that will simultaneously develop quantitative literacy and spark an interest in STEM fields. NCTM President Mike Shaughnessy points out that the current "layer cake of algebra-dominated mathematics" exists solely to prepare students for calculus, and he offers four concrete alternative pathways:

1. Data analysis, combinatorics, probability and numerical trends/modeling.

2. Statistical thinking and decision making.

3. Linear algebra.

4. Multivariate applications of calculus and statistics.

Quantitative Reasoning courses can provide the necessary foundation for this mathematics curriculum, building and developing the critical middle school mathematics topics that currently are abandoned in high school but serve as the foundation for numeracy. In addition, a QR course can deepen algebraic reasoning through intentional teaching utilizing spreadsheets for data analysis and modeling.

\section{Developing QR Curricula}

My background in QR includes both teaching and assessing QR spanning the entire K-16 curriculum:

- teaching and developing a QR course for college students which has led to the writing of a QR textbook, Thinking Quantitatively (Gaze, in preparation),

- creating and developing the curriculum for a Masters in Numeracy Program for K-12 teachers at Alfred University (Gaze 2010), 
- working as Principal Investigator on an NSF-funded TUES Type I project, Quantitative Literacy and Reasoning Assessment (QLRA), DUE: 1140562, 2/15/12-1/31/14.

Over the last four years I have had the opportunity to work with many partners on QR curriculum initiatives including the Carnegie Foundation's Quantway project, the Dana Center at UT Austin's National Math Pathways project, and QR curriculum development projects with the community college systems in the states of Indiana and North Carolina. These diverse projects have all led to the development of QR curricula that are remarkably consistent. There are three main content areas that are incorporated into the QR courses:

1. Proportional Reasoning

2. Probability and Statistics

3. Modeling

The course outcomes and objectives are all similar to those written by Ivy Tech Community College faculty in Indiana:

Upon successful completion of this course the student will be expected to define problems clearly, identify relevant information, ask pertinent questions, and support conclusions using persuasive quantitative reasoning. Students will be able to:

1. Use and interpret ratios in all their guises: rates/percentages/decimals.

2. Use proportional reasoning in context (real world data sets), including scale and similarity.

3. Operate within and between different measurement scales including unit conversion and dimensional analysis.

4. Use estimation, check reasonableness of answers, and evaluate precision and accuracy of data.

5. Use and interpret percentages in various forms: probability, risk, rates of return, percentiles, and relative frequency.

6. Develop fundamental financial literacy including annual percentage rates, periodic rates, loans (amortization tables), retirement (annuities).

7. Compute, contrast, and interpret absolute and relative change, including margin of error.

8. Explore and interpret rates of change, contrasting linear versus exponential growth (simple versus compound interest).

9. Interpret visual representations of data, examine statistical arguments including sampling, correlation and causation. 
10. Analyze real world data through descriptive statistics (measures of central tendency and dispersion), normal distributions, and z-scores.

11. Use algebraic reasoning to explore relationships between variables, including the construction and use of equations to solve problems, i.e. modeling.

12. Research and select appropriate formulas/strategies to solve real world problems. Solve a variety of application problems in the above areas.

13. Use relevant mathematical language, laws, and notations appropriately.

14. Use a scientific calculator proficiently as related to coursework.

15. Use computer technology, which may include the Internet, spreadsheets, or computer tutorials/simulations to enhance the course objectives.

\section{Conclusion}

The above-listed QR curriculum focuses first on the key numeracy skill set of proportional reasoning by systematically developing the concepts of unit, scale, fraction, percent, proportion, decimal, and rate around the common theme of ratio. This foundation leads to higher-order quantitative reasoning via modeling, with statistical literacy guiding the exploration and study of data. Spreadsheets offer an easy entry into modeling with computers, while at the same time developing students' algebraic reasoning.

\section{References}

Bennett, Jeffrey. 2012. Math for Life: Crucial Ideas You Didn’t Learn in School. Greenwood Village, CO. Roberts and Company Publishers.

Blair, Richelle, Ellen E. Kirkman, and James W. Maxwell. 2013. Conference Board of Mathematical Sciences (CBMS) Survey Reports 2010. American Mathematical Society, 374 pp. http://www.ams.org/profession/data/cbmssurvey/cbms2010 (accessed 26 Oct 2013)

Gaze, Eric. 2010. Creating a Masters in Numeracy Program. Numeracy 3 (2), Article 8. http://dx.doi.org/10.5038/1936-4660.3.2.8 (accessed 15 Nov 2013). . 2012. Review of Math for Life by Jeffrey Bennett. Numeracy 5 (2), Article 7. http://dx.doi.org/10.5038/1936-4660.5.2.7 (accessed 15 Nov 2013). —. In preparation. Numeracy: A Quantitative Literacy, Communicating with Numbers. Boston, MA: Pearson Publishing. 